OPEN ACCESS

Edited by:

Roxanne Beinart,

The University of Rhode Island,

United States

Reviewed by:

Philippe Vandenkoornhuyse,

University of Rennes 1, France

Alison Gould,

California Academy of Sciences,

United States

*Correspondence:

Anouk van 't Padje

anouk.vantpadje@wur.n

E. Toby Kiers

toby.kiers@VU.nl

Specialty section:

This article was submitted to

Coevolution

a section of the journal

Frontiers in Ecology and Evolution

Received: 01 October 2020

Accepted: 23 February 2021

Published: 06 April 2021

Citation:

van 't Padje A, Bonfante $P$,

Ciampi LT and Kiers ET (2021)

Quantifying Nutrient Trade

in the Arbuscular Mycorrhizal

Symbiosis Under Extreme Weather

Events Using Quantum-Dot Tagged

Phosphorus.

Front. Ecol. Evol. 9:613119.

doi: 10.3389/fevo.2021.613119

\section{Quantifying Nutrient Trade in the Arbuscular Mycorrhizal Symbiosis Under Extreme Weather Events Using Quantum-Dot Tagged Phosphorus}

\author{
Anouk van 't Padje1,2*, Paola Bonfante's, Luisa Tartaglia Ciampi3 and E. Toby Kiers²* \\ 1 Laboratory of Genetics, Department of Plant Sciences, Wageningen University \& Research, Wageningen, Netherlands, \\ ${ }^{2}$ Department of Ecological Science, Vrije Universiteit, Amsterdam, Netherlands, ${ }^{3}$ Department of Life Science and Systems \\ Biology, University of Turin, Turin, Italy
}

Given the current trends in climate change, extreme weather events are expected to increase in strength and frequency. Such events can impact species survival and species interactions. One of the most ubiquitous symbioses on earth is the nutrient exchange partnership between arbuscular mycorrhizal fungi and their host plants. While past work has shown that mycorrhizal fungi can help alleviate stress, it is unknown how phosphorus uptake by plants to fungi is affected by extreme weather events, such as flooding and heat waves. To test this response, we grew Medicago truncatula host plants with or without mycorrhizal fungi and then exposed them to extreme weather treatments: increasing soil temperature by $12^{\circ} \mathrm{C}$, or by flooding the plant roots for 7 days. We measured plant and fungal performance, and quantified phosphorus $(P)$ uptake before and after extreme weather treatments using a technique in which we tagged apatite, a form of rock phosphorus, with fluorescing quantumdots (QDs) nanoparticles. We then measured fluorescence in root and shoot tissue at harvest. We found that plants and arbuscular mycorrhizal fungi were affected by soil flooding, with plant survival, fungal colonization and QD-apatite uptake decreasing under flooded conditions. We did not see these negative effects in the heat treatment. While the presence of arbuscular mycorrhizal fungi affected plant biomass allocation, leading to an increase in shoot biomass, the symbiosis did not increase plant survival, total biomass or QD uptake in either treatment. More generally, we found host tissue contained roughly $80 \%$ more QD-apatite from the pre-treatment compared to the post-treatment nutrient injection. Future studies should focus on various plant-fungal combinations to create databases on which predictive models to extreme weather events can be constructed. 


\section{INTRODUCTION}

As the climate continues to warm, global ecosystems are experiencing an increase in the frequency and intensity of extreme weather events, such as sudden heat waves, droughts, torrential rains, and floods (IPCC, 2014; Allen et al., 2018). Extreme weather events can have dramatic impacts on the survival, abundance and distribution of species, and can even lead to the local extinction of species (Tinsley et al., 2015; Ray et al., 2016; Zylstra et al., 2019). While progress is being made in our ability to predict the effects of extreme weather events on single species, it is less understood how these events affect the interactions among species, such as in mutualism and parasitism (Harrison, 2000; Edwards and Richardson, 2004; Bronstein, 2015; Millar and Bennett, 2016; Gardner et al., 2017). Sequential extreme weather events can drive symbiotic interactions between species to break down (Rosenzweig et al., 2015), for example by disrupting partner services (Zhou et al., 2013). Likewise, partner abundance can affect the stability of mutualisms with mutualism losses occurring where symbionts are scarce (Chomicki and Renner, 2017). Changes in these species interactions can, in turn, affect species richness and ecosystem resilience, but this is not well understood (Chomicki et al., 2019). A key goal of global change research is to understand how changes in species interactions can be magnified at the ecosystem level (Dakos and Bascompte, 2014; Jordano, 2016).

One of the most ubiquitous species interactions on earth is the symbiosis formed between $\sim 70 \%$ of all terrestrial plants and arbuscular mycorrhizal fungi of the Glomeromycotina, a subphylum of the Mucoromycota (Spatafora et al., 2016; Brundrett and Tedersoo, 2018; Tedersoo et al., 2020). Arbuscular mycorrhizal fungi play a key role in nutrient cycling by forming an underground link between plants roots and soil bound nutrients. The fungi forage the soil for mineral nutrients and exchange these nutrients with host plants for sugars and fatty acids (Smith et al., 2011; Berruti et al., 2016; Jiang et al., 2017; Keymer et al., 2017; Luginbuehl et al., 2017). In addition to this role in nutrient provisioning, there is a growing body of research demonstrating how arbuscular mycorrhizal fungi can protect host plants from biotic and abiotic stress (Mohan et al., 2014; $\mathrm{Wu}, 2017$ ), including increased pathogen resistance (MartinezMedina et al., 2016; Chialva et al., 2018), chemical tolerance (Meier et al., 2015), heavy metal protection (Husna et al., 2016), and mediation of salinity (Wu et al., 2010).

Given this important role in stress protection, a major question in the field is whether arbuscular mycorrhizal fungi can help mitigate the effects of extreme weather events, or if extreme weather events could drive a breakdown of the interaction. Our aim was to mimic a heat wave and a flooding event in mycorrhizal and non-mycorrhizal plants and to determine the effect of extreme weather events on the phosphorus (P) uptake, plant growth, and fungal success (as measured by copy number). To mimic a flood, we submerged replicates of the model species Medicago truncatula with water levels rising $0.5-1.0 \mathrm{~cm}$ above the soil for 7 days. To mimic a heat wave, we increased soil temperature from 28 to $40^{\circ} \mathrm{C}$ for 7 days using heating mats regulated with a digital thermostat.
We employed a new technique to study nutrient transfer in both mycorrhizal and non-mycorrhizal plants in which we tagged apatite, a natural form of rock $\mathrm{P}$, with highly fluorescent quantum-dots (QDs) to create fluorescing QD-apatite (Whiteside et al., 2019; van't Padje et al., 2020a). QDs are nanoparticles that fluoresce in bright and pure colors when excited with UV light. We used a class of QDs in which a carboxyl polymer creates a protective coat to prevent organisms from being exposed to the toxicity of the heavy metal core, and allows us to conjugate the apatite to QDs. Past work has demonstrated that QD-apatite can be taken up by the fungal networks of in vitro root organ cultures, and transferred to host roots (Figure 1; Whiteside et al., 2019; van't Padje et al., 2020a,b). Similarly, QD-apatite can be taken up by the roots of whole-plants, but colonization by mycorrhizal fungi seem to increase this uptake (Whiteside et al., 2019). The exact uptake mechanism of QD-apatite by the fungus is still not known. However, various controls performed in past experiments have confirmed that fungi show no uptake affinity for unbound (i.e., unconjugated) QDs or for bare metal QD cores (i.e., "naked quantum dots"), meaning that the fungus will not take up QDs if they are not conjugated to a nutrient source like apatite (Whiteside et al., 2019). Further validations have shown that there are no differences in uptake and transfer affinity among different colors of QD-apatite, and that whole plants grown on QD-apatite show no signs of toxicity compared to plants growing on apatite lacking QD-cores (i.e., not conjugated to any QDs) (Whiteside et al., 2019).

Here, we injected sterile sand with QD-apatite of two distinct colors, adding one color to the sand as a pre-treatment (red, $\lambda=663 \mathrm{~nm}$ ) and one color as a post-treatment (yellow, $\lambda=572 \mathrm{~nm}$ ). This allowed us to determine QD-apatite uptake of plants before and after an extreme weather event. We expected that the QD-apatite uptake would decrease in plants exposed to extreme weather treatments, but that this effect would be reduced in plants colonized by arbuscular mycorrhizal fungi.

\section{MATERIALS AND METHODS}

\section{Germination, Fungal Inoculation and Growing Conditions}

We sterilized and scarified seeds of $M$. truncatula (Institut National de la Recherche Agronomique, Montpellier, France) by submerging the seeds in $95 \% \mathrm{H}_{2} \mathrm{SO}_{4}$ for $6.5 \mathrm{~min}$. We removed the acid by rinsing the seeds with $\mathrm{dH}_{2} \mathrm{O}$ six times. We stored the seeds at $4^{\circ} \mathrm{C}$ in the dark for 4 days (Garcia et al., 2006). After 4 days, we placed four germination seeds per pot $(75 \mathrm{~mL} ; d=6 \mathrm{~cm})$, containing autoclaved RHP Agra-vermiculite (M3). We watered them with $25 \mathrm{~mL}$ of an $50 \% \mathrm{P}$ modified Hoagland's solution $\left(6.5 \mathrm{mM} \mathrm{KNO}_{3}\right.$, $\left.3.25 \mathrm{mM} \mathrm{K}_{2} \mathrm{SO}_{4}, 4 \mathrm{mM} \mathrm{Ca}\left(\mathrm{NO}_{3}\right)_{2} \cdot 4 \mathrm{H}_{2} \mathrm{O}\right), 4 \mathrm{mM} \mathrm{CaCl} 2 \cdot 2 \mathrm{H}_{2} \mathrm{O}$, $4 \mathrm{mM} \mathrm{CaSO} \cdot 2 \mathrm{H}_{2} \mathrm{O}, 0.5 \mathrm{mM} \mathrm{NH}_{4} \mathrm{NO}_{3}, 1 \mathrm{mM} \mathrm{NH}_{4} \mathrm{H}_{2} \mathrm{PO}_{4}$, $1 \mathrm{mM} \mathrm{KH} \mathrm{PO}_{4}, 1 \mathrm{mM} \mathrm{MgSO} \cdot 6 \mathrm{H}_{2} \mathrm{O}, 50 \mu \mathrm{M} \mathrm{KCl}, 35 \mu \mathrm{M}$ $\mathrm{H}_{3} \mathrm{BO}_{3}, 25 \mu \mathrm{M}, 2 \mu \mathrm{M} \mathrm{MnSO} \cdot 4 \mathrm{H}_{2} \mathrm{O}, 2 \mu \mathrm{M} \mathrm{ZnSO} \cdot 7 \mathrm{H}_{2} \mathrm{O}$, $0.5 \mu \mathrm{M} \mathrm{CuSO} \cdot 5 \mathrm{H}_{2} \mathrm{O}, 5 \mu \mathrm{M}\left(\mathrm{NH}_{4}\right)_{6} \mathrm{Mo}_{7} \mathrm{O}_{24} \cdot 4 \mathrm{H}_{2} \mathrm{O}, 20 \mathrm{mM}$ $\mathrm{Fe}(\mathrm{Na})$ EDTA $\left(\mathrm{C}_{10} \mathrm{H}_{12} \mathrm{~N}_{2} \mathrm{O}_{8} \mathrm{FeNa}\right)$ (Hoagland and Arnon, 1950; Werner et al., 2018). We placed the pots in a climate room, under 

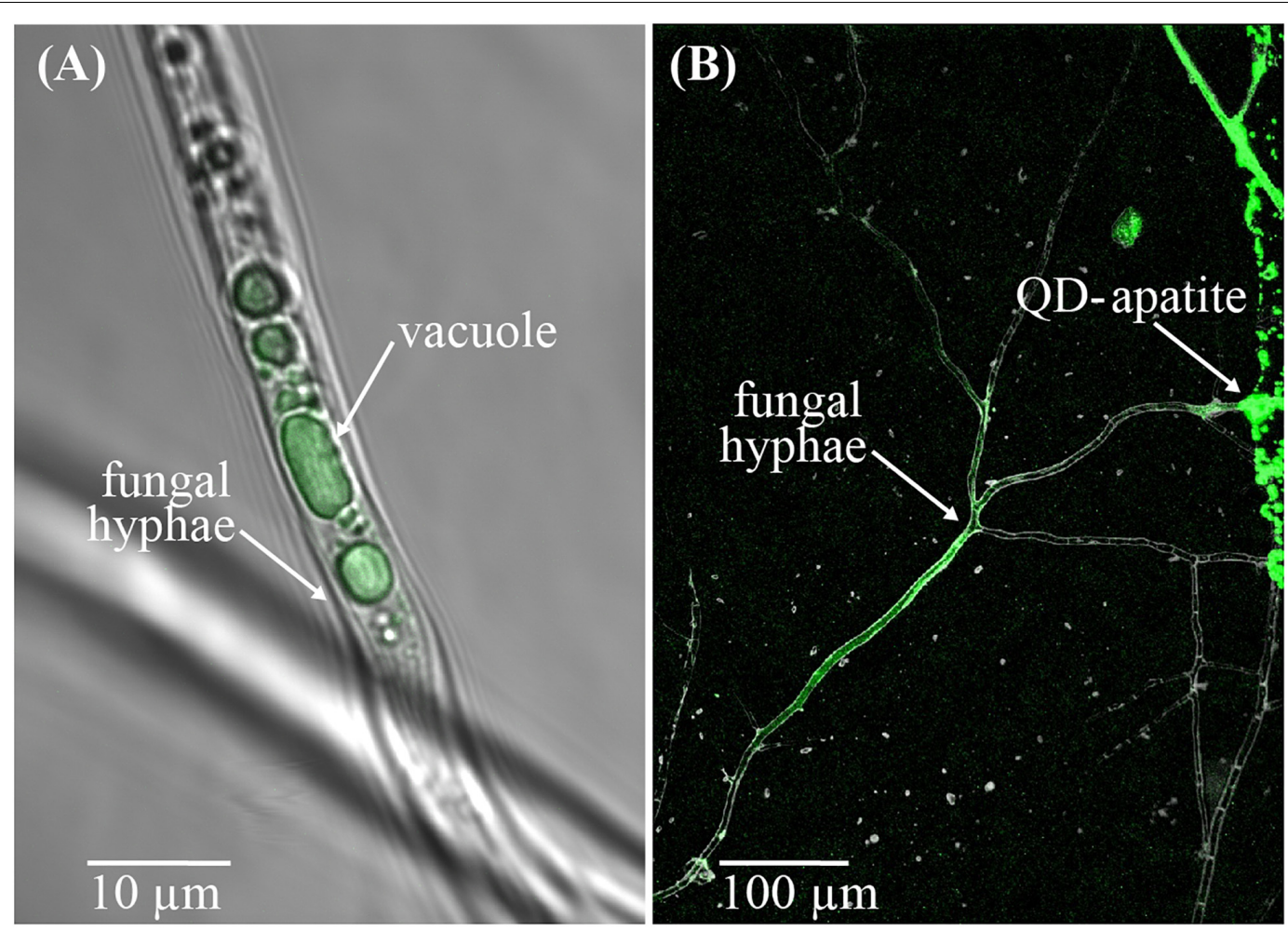

FIGURE 1 | QD-apatite uptake by arbuscular mycorrhizal fungus Rhizophagus irregularis. (A) Image of a fungal hypha from an in vitro culture with QD-apatite in its vacuoles. (B) Image of the arbuscular mycorrhiza fungus Rhizophagus irregularis near a patch of QD-apatite. Courtesy of M. D. Whiteside.

a light intensity of $170 \mu \mathrm{mol} \cdot \mathrm{m}^{-2} \cdot \mathrm{s}^{-1}$. We covered the seeds for the first 3 days and then shaded the seedlings for the following 7 days. After 10 days, we selected healthy seedlings, rinsed the roots with $\mathrm{dH}_{2} \mathrm{O}$ and transferred them to plastic pots $(320 \mathrm{~mL})$ containing $\sim 270 \mathrm{~g}$ of quartz sand $(>99.5 \% \mathrm{SiO} 2)$.

We prepared fungal inoculum by homogenizing mature in vitro root organ cultures of the arbuscular mycorrhizal fungus Rhizophagus irregularis (strain A5 Sanders Lab) grown on $\mathrm{Ri}$ T-DNA L-transformed carrot roots (Daucus carota) (Declerck et al., 2005). We inoculated half of the seedlings with $1.70 \mathrm{~mL}$ inoculum ( $\sim 1000$ spores), and the other half with $1.70 \mathrm{~mL} \mathrm{dH}_{2} \mathrm{O}$. We then fertilized all seedlings with $5 \mathrm{~mL} 50 \% \mathrm{P}$ modified Hoagland's solution. We covered the sand with autoclaved white plastic beads, and placed each pot in a transparent plastic beaker $(550 \mathrm{~mL})$ to allow for flooding. We grew plants in a controlled climate room with a day-night cycle of $16-8 \mathrm{~h}$, a day temperature of $22^{\circ} \mathrm{C}$ and a night temperature of $17^{\circ} \mathrm{C}$. We kept the humidity at $75 \%$ and provided the plants with full spectrum day-light gas-discharge lamps with an intensity of $550 \mu \mathrm{mol} \cdot \mathrm{m}^{-2} \cdot \mathrm{s}^{-1}$ at plant height (Barker et al., 2006). We watered plants twice a week with sterile $\mathrm{dH}_{2} \mathrm{O}$ (Barker et al., 2006) to maintain a soil water content of $18 \%$ by weighting until 6 weeks, after which we increased the soil water content to $24 \%$ of the water holding capacity. Once per 2 weeks, we fertilized plants with $25 \mathrm{~mL}$ 50\% P modified Hoagland's solution per pot. Mycorrhizal and non-mycorrhizal plants were randomly distributed in the climate room, and assigned to one of the three treatments: control, flooding, or heat. We grew a total of 72 plants, with 12 replicates per mycorrhizal $\times$ extreme weather treatment.

\section{Nutrient Injections and Extreme Weather Treatments}

We prepared two solutions of red $(\lambda=663 \mathrm{~nm})$ and yellow $(\lambda=572 \mathrm{~nm}) \mathrm{QD}$-apatite to determine pre- and post-treatment nutrient uptake. To conjugate the QDs with hydroxyapatite, we added 150 mg Carboxyl CdSeS/ZnS Nanocrystals (CrystalPlex, Pittsburgh, PA, United States) of each color to 1 L 50\% modified simulated body fluid-50\% simulated body fluid solution $(11.992 \mathrm{~g}$ $\mathrm{NaCl} ; 1.966 \mathrm{~g} \mathrm{NaHCO}_{3} ; 0.447 \mathrm{~g} \mathrm{KCl} ; 0.457 \mathrm{~g} \mathrm{MgCl}_{2} \cdot 6 \mathrm{H}_{2} 0 ; 0.261 \mathrm{~g}$ $\mathrm{K}_{2} \mathrm{HPO}_{4} ; 0.416 \mathrm{~g} \mathrm{CaCl}_{2} ; 0.106 \mathrm{~g} \mathrm{Na}_{2} \mathrm{SO}_{4}$ ) (Tang et al., 2010; Kawashita et al., 2012) and performed two separate reactions in the dark at $37^{\circ} \mathrm{C}$. In the first reaction, small $(\sim 8 \mathrm{~nm})$ QD crystals were formed during $24 \mathrm{~h}$. In the second reaction, the smaller crystals conjugated to bigger crystals $(\sim 200 \mathrm{~nm})$ during an exposure for $60 \mathrm{~h}$, creating $15.64 \mathrm{~g}$ apatite per L (Kawashita et al., 2012), closely mimicking natural apatite (Sun et al., 2014). In between crystal formation, we placed the solutions on a shaker (100 oscillations/minute) for $24 \mathrm{~h}$ at room temperature. We replaced $80 \%$ of the supernatant with nanopure $\mathrm{H}_{2} \mathrm{O}$ twice to remove unbound reagents, shaking the solutions by hand to reprecipitate between the washing steps. Our past analyses suggest that each nmol of QD-apatite contains $\sim 700$ nmols of P (nmol 
$\mathrm{P}: \mathrm{QD}=708: 1)$-for a complete description of the hydroxyapatite conjugation steps and validation tests, see Whiteside et al. (2019).

Five weeks after seedling transfer, we injected $5.7 \mathrm{~mL}$ red QDapatite in the soil (0.33 g apatite/1000 $\mathrm{g}$ soil) for pre-treatment. This injection allowed us to determine baseline nutrient transfer before the plants were exposed to the treatments. After injection, we reduced fertilization to $12.5 \mathrm{~mL} 50 \% \mathrm{P}$ modified Hoagland's solution per pot once per 2 weeks to stimulate QD-apatite uptake. We then allow plants to grow for 4 weeks before we started the treatments.

Treatments were initiated on adult plants, 9 weeks after seedling transfer. To mimic a flood, we submerged individual plants by adding $\mathrm{dH}_{2} \mathrm{O}$ into the transparent beakers of 12 mycorrhizal and 12 non-mycorrhizal plants. We submerged the plants with water level rising $0.5-1 \mathrm{~cm}$ above the soil for 7 days. To mimic a heat wave, we placed 12 mycorrhizal and 12 non-mycorrhizal plants randomly on two heating mats (Bio Green GmbH \& Co. KG, Bischoffen-Oberweidbach, Germany). The heating mats were regulated by a digital thermostat, which measured the soil temperature in the pot. We increased soil temperature from $28^{\circ} \mathrm{C}$ until $40^{\circ} \mathrm{C}$ for 7 days, keeping the original watering regime. After 1 week of the extreme weather treatments, we removed the water from the beakers of the flooded plants and placed the heat-treated plants randomly in the climate chamber. 12 mycorrhizal and 12 non-mycorrhizal plants were randomly assigned to a control treatment in which no extreme weather event was initiated. These controls plants were exposed to the same nutrient and green house conditions as the extreme weather plants, but were not exposed to flooding or heat treatments. Directly (same day) after the extreme weather treatments (or notreatment in the case of the controls), we injected $2.5 \mathrm{~mL}$ yellow QD-apatite per pot ( $0.166 \mathrm{mg}$ apatite/1000 g soil) to study if and how the nutrient transfer was influenced by the treatments as measure by the post-treatment QD-apatite injection.

\section{Harvest}

We harvested plants 11 weeks after seedling transfer, 7 days after the post-treatment QD-apatite injection. We washed roots in $\mathrm{dH}_{2} \mathrm{O}$ and separated the root and shoot at the rosette. We placed plant material in paper bags to dry at $50^{\circ} \mathrm{C}$ for $48 \mathrm{~h}$. We measured the dry mass of roots and shoot on an analytical balance, and subsampled root material for qPCR analysis of intraradical fungal colonization ( $\sim 20 \mathrm{mg}$ ) and root and shoot material for fluorescent analysis ( $\sim 6 \mathrm{mg}$ ) to determine the amount of QDapatite in the tissue. We pulverized subsamples of root and shoot material using glass beads and a bead-beater speeding on $4 \mathrm{~m} / \mathrm{s}$ for $40 \mathrm{~s}$ (Thermo Savant FastPrep Fp120 Cell homogenizer).

\section{DNA Isolation and Real Time qPCR}

To quantify intraradical colonization, we extracted DNA from roots, using a modified protocol of the DNeasy Plant Mini Kit by Qiagen kit (Qiagen, Hombrechtikon, Switzerland), which included the addition of $10 \mu \mathrm{L}$ internal standard, a plasmid containing cassava mosaic virus DNA (Engelmoer et al., 2014) after the lysis step to be able to correct for extraction efficiency (Kiers et al., 2011; Whiteside et al., 2019). We stored extracted DNA at $-20^{\circ} \mathrm{C}$ for further analysis. We used Real Time qPCR to determine intraradical colonization of the host roots (Thonar et al., 2012). We prepared DNA samples by diluting the root samples 100 times to dilute PCR inhibiting proteins, and added $10 \mu \mathrm{L}$ iTaq universal SYBR Green Supermix (Bio-Rad, Hercules, CA, United States), $0.32 \mu \mathrm{L}$ forward primer, $0.32 \mu \mathrm{L}$ reverse primer, $0.080 \mu \mathrm{L}$ probe, and $5.28 \mu \mathrm{L}$ nanopure water to each DNA sample of $4 \mu \mathrm{L}$ sample (Kiers et al., 2011). We loaded the prepared DNA samples into white welled 96-well PCR plates (Bio-Rad, Hercules, CA, United States) and placed the samples in a CFX96 Real-Time PCR Detection System (Bio-Rad, Hercules, CA, United States). We measured the presence of $R$. irregularis and internal standard using two separate qPCR rounds for each sample. For the internal standard, we used the following cycle: denaturation at $95^{\circ} \mathrm{C}$ for $5 \mathrm{~s}$, annealing at $50^{\circ} \mathrm{C}$ for $30 \mathrm{~s}$ and amplification at $72^{\circ} \mathrm{C}$ for $1 \mathrm{~s}$. For $R$. irregularis, we used a cycle of denaturation at $95^{\circ} \mathrm{C}$ for $5 \mathrm{~s}$, and at $50^{\circ} \mathrm{C}$ for $30 \mathrm{~s}$, replicated 39 times. We exported $\mathrm{Cq}$ values with the CFX manager software, and set a baseline threshold of 500 relative fluorescent units. We converted Cq values to copy numbers (Kiers et al., 2011) and calculated extraction efficiency by dividing the Cq values of $R$. irregularis by the Cq value of the internal standard.

\section{Fluorescent Analysis}

We determined QD-apatite content of root and shoot material by measuring emission spectrum of plant tissue. We prepared the ground plant material by adding $150 \mu \mathrm{L} 10 \mathrm{mM}$ borate buffer per mg plant material. From each sample, we pipetted five replicates of $150 \mu \mathrm{L}$ in a 96 wells plate with a glass bottom (Eppendorf AG, Hamburg, Germany). To reduce edge effects, we left the outmost wells empty. We measured the emission using a fluorescence a BioTek Synergy MX plate reader with Gen5 ${ }^{\text {TM }}$ Data Analysis Software. Emission of root and shoot material was calculated from 450 to $800 \mathrm{~nm}$, with steps of $2 \mathrm{~nm}$ by an excitation of $325 \mathrm{~nm}$. We then translated the emission spectra to specific QD-apatite content in root and shoot using emission finger printing. This allowed us to separate the emission of the two QD colors, and the auto-fluorescence of the plant material (Zimmermann et al., 2003), using a custom script in Matlab Code (MathWorks, Natick, MA, United States) (Whiteside et al., 2019). We converged fluorescence intensities into the concentration of QD-apatite in root and shoot using calibration gradients of QDs of each color, composed of seven concentrations: $13.1 \mathrm{mM}$, $9.83 \mathrm{mM}, 7.37 \mathrm{mM}, 5.53 \mathrm{mM}, 4.15 \mathrm{mM}, 3.11 \mathrm{mM}$, and $2.33 \mathrm{mM}$ (Whiteside et al., 2012a).

\section{Statistical Analysis}

All statistical analyses were performed in $\mathrm{R}$ version 3.3.4, with each treatment compared directly to the control. We first analyzed plant survival with a generalized linear model with a binomial error distribution, with the treatment (control, flood, or heat) and mycorrhizal status (mycorrhizal and non-mycorrhizal) as independent variables. This allowed us to produce ANOVA type III tables with a likelihood ratio as test statistic. We then removed dead plants from the dataset for further analysis. We analyzed the effect of the independent variables (treatment, mycorrhizal status and the treatment $\times$ mycorrhizal status interaction) on total biomass, root and shoot mass with an 
ANOVA and an $F$ test. We used an ANOVA with an $F$ test on a generalized linear model with a gaussian error distribution to analyze intraradical colonization per mg of root. We used Wilcoxon rank sum tests to analyze the difference in nmol of pretreatment QD-apatite between mycorrhizal and non-mycorrhizal plants per mg of root and shoot material (the difference in QDapatite content of the root and shoot and the difference in uptake from the pre- and post-treatment), injection. We calculated the logarithm of the summed QD-apatite content of shoot and root as the total QD content and analyzed the effect of the independent variables with an ANOVA.

\section{RESULTS}

\section{Plant Survival}

We found that both heat and flooding treatments significantly influenced plant survival. At harvest, 11 weeks after seedling transfer, $63 \%$ of the flooded plants (15 of 24 ) and $21 \%$ of the heated plants (5 of 24) had died. In contrast, 100\% (all 24) of the control plants survived. We found no evidence that mycorrhizal status of the plants significantly influenced overall plant survival (Table 1). Of the surviving flooded plants, four were mycorrhizal, and five non-mycorrhizal. In the heat treatment, eight mycorrhizal plants survived to harvest, and eleven non-mycorrhizal plants.

\section{Plant Growth}

We determined the effect of extreme weather treatments on plant growth by measuring plant biomass at harvest, removing the plant replicates that had died. We first compared the control to the heat treatment, with and without mycorrhizal fungi. Total plant biomass was not significantly affected by the heat treatment, the mycorrhizal status or the treatment $\times$ mycorrhizal status interaction (Table 1). The root biomass was also not significantly affected by the treatment, mycorrhizal status or treatment $\times$ mycorrhizal status interaction (Table $\mathbf{1}$ and Figure 2A). However, while shoot biomass was not significantly affected by treatment effect, we found a significant mycorrhizal effect, with mycorrhizal plants having bigger shoots, independent of treatment (no significant treatment $\times$ mycorrhizal status interaction, Table $\mathbf{1}$ and Figure 2B).

We then analyzed the effect of the flooding treatment on the biomass by comparing the control to the flooding treatment. Total biomass was significantly affected by the treatment, with flooded plants having a lower total biomass. However, total biomass was not significantly affected by mycorrhizal status or the treatment $\times$ mycorrhizal interaction (Table 1). Root biomass was likewise significantly lower in flooded plants, but there was no significant effect of mycorrhizal status or the treatment $\times$ mycorrhizal status interaction (Table $\mathbf{1}$ and Figure 2C). The shoot mass was not significantly influenced by treatment or mycorrhizal status, but was significantly affected by the treatment $\times$ mycorrhizal status interaction: shoots of flooded mycorrhizal plants were larger than shoots of non-mycorrhizal flooded plants (Table 1 and Figure 2D).

\section{Fungal Colonization}

We examined how extreme weather treatments affected intraradical fungal colonization on host roots. We compared the heat-treated plants with the control plants, and found no

TABLE 1 | Analysis of variance on the biomass of plants.

\begin{tabular}{|c|c|c|c|c|c|c|c|}
\hline \multirow[b]{3}{*}{ Plant survival } & \multicolumn{7}{|c|}{ Extreme weather treatment } \\
\hline & \multicolumn{4}{|c|}{ Heat } & \multicolumn{3}{|c|}{ Flood } \\
\hline & & & $x^{2}$ & $p$-value & & $x^{2}$ & $p$-value \\
\hline Extreme weather treatment & & & 6.3506 & 0.0117 & & 15.276 & $0.001^{*}$ \\
\hline Mycorrhizal status & & & 0.000 & 1.000 & & 0.000 & 1.000 \\
\hline Treatment $\times$ mycorrhizal status interaction & & & 0.000 & 1.000 & & 0.000 & 1.000 \\
\hline Total plant biomass & Df & res & $F$-value & $p$-value & res & $F$-value & $p$-value \\
\hline Extreme weather treatment & 1 & 39 & 0.011 & 0.917 & 29 & 11.611 & $0.002^{*}$ \\
\hline Mycorrhizal status & 1 & 39 & 0.427 & 0.517 & 29 & 0.292 & 0.593 \\
\hline Treatment $\times$ mycorrhizal status interaction & 1 & 39 & 0.109 & 0.743 & 29 & 0.088 & 0.769 \\
\hline Root biomass & Df & res & $F$-value & $p$-value & res & $F$-value & $p$-value \\
\hline Extreme weather treatment & 1 & 39 & 0.323 & 0.573 & 29 & 10.852 & $0.003^{\star}$ \\
\hline Mycorrhizal status & 1 & 39 & 0.003 & 0.958 & 29 & 0.073 & 0.789 \\
\hline Treatment $\times$ mycorrhizal status interaction & 1 & 39 & 0.038 & 0.846 & 29 & 0.420 & 0.522 \\
\hline Shoot biomass & Df & res & $F$-value & $p$-value & res & $F$-value & $p$-value \\
\hline Extreme weather treatment & 1 & 39 & 1.933 & 0.172 & 29 & 1.727 & 0.199 \\
\hline Mycorrhizal status & 1 & 39 & 5.417 & $0.025^{\star}$ & 29 & 3.792 & 0.061 \\
\hline Treatment $\times$ mycorrhizal status interaction & 1 & 39 & 2.862 & 0.099 & 29 & 4.682 & $0.039 *$ \\
\hline
\end{tabular}

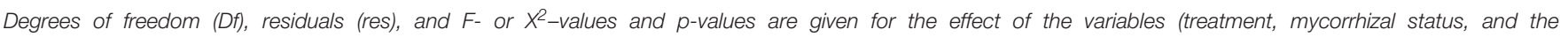
treatment $\times$ mycorrhizal status interaction). P-values in bold with an * have a significant effect of the variable $(p$-value $<0.05)$. 

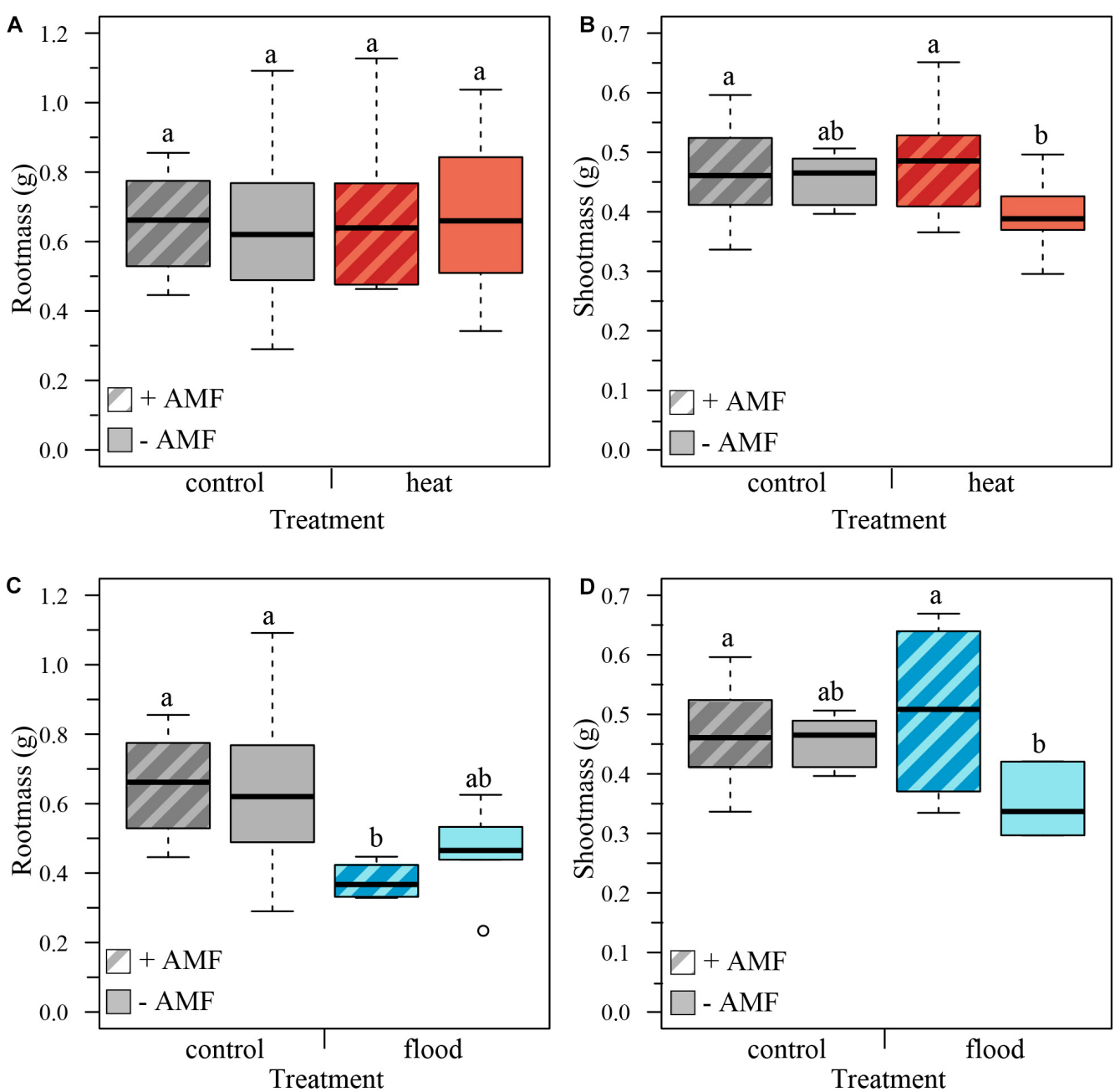

FIGURE 2 | Boxplots representing the plant biomass per treatment for mycorrhizal (+AMF) and non-mycorrhizal plants (-AMF). (A) Root biomass was not significantly influenced by heat treatment, mycorrhizal status or the treatment $\times$ mycorrhizal status interaction. (B) Shoot mass was not significantly influenced by the heat treatment nor the treatment $\times$ mycorrhizal status interaction, but was affected by the mycorrhizal status, with mycorrhizal plants having higher shoot biomass. (C) Root biomass was significantly affected by the flooding treatment, with flooded plants showing lower root biomass, but not by mycorrhizal status or treatment $\times$ mycorrhizal interaction. (D) Shoot biomass was not significantly affected by flooding treatment or mycorrhizal status but was significantly affected by the treatment $\times$ mycorrhizal status interaction: shoots of flooded mycorrhizal plants were significantly larger than shoots of flooded non-mycorrhizal plants.

$n_{\text {contol, }+ \text { AMF }}=12, n_{\text {contol, }}$-AMF $=12, n_{\text {heat },+ \text { AMF }}=8, n_{\text {heat, }}$-AMF $=11, n_{\text {flood },+ \text { AMF }}=4, n_{\text {flood, }}$-AMF $=5$. Top and bottom of the box indicate the first and third quartile, and the whiskers indicate the minimum and maximum values. Different letters indicate significant difference between the means $(p-v a l u e ~<0.05)$.

significant effect of treatment on the intraradical colonization per mg of root, or per total root (Table 2 and Figures $3 \mathbf{A , B}$ ). In contrast, when we compared the flooded plants with the control plants, we found a significant treatment effect, with flooding associated with a $58 \%$ drop in colonization per root and $94 \%$ drop in colonization per mg root (Table 2 and Figures 3C,D).

\section{QD-Apatite Uptake Before Exposure to Treatment (Pre-treatment)}

We determined the QD status of plants before exposure to the extreme weather treatments by quantifying the red $\lambda=666 \mathrm{~nm}$ nmol QD-apatite per total root and total shoot tissue. Based on this pre-treatment injection, we found that mycorrhizal status did not significantly influence nmol of QD-apatite per total root (Wilcoxon rank sum test, $W=314, p=0.696$ ) or shoot (Wilcoxon rank sum test, $W=234, p=0.062$ ). In terms of allocation of QD-apatite across the plant, we found that total shoot contained on average three times more QDapatite $(\lambda=2.603, \mathrm{SE}<0.187 \mathrm{nmol} /$ total shoot $)$ than total root $(\lambda=0.889, \mathrm{SE}<0.059 \mathrm{nmol} /$ total root, paired Wilcoxon rank sum test: $W=317, p \leq 0.0001$, Figures 4A,B).

\section{QD-Apatite Uptake After Exposure to Treatment (Post-treatment)}

We then quantified the post-treatment uptake by measuring the yellow, $\lambda=572 \mathrm{~nm}$, QD-apatite in the host plants. We found that plants contained, on average, $80 \%$ less post-treatment $\mathrm{QD}$-apatite compared to pre-treatment injection, independent of treatment. 
TABLE 2 | Analysis of variance on the intraradical colonization and QD-apatite content per total root and total shoot.

\begin{tabular}{|c|c|c|c|c|c|c|c|}
\hline \multirow[b]{3}{*}{ Intraradical colonization per mg root } & \multicolumn{7}{|c|}{ Extreme weather treatment } \\
\hline & \multicolumn{4}{|c|}{ Heat } & \multicolumn{3}{|c|}{ Flood } \\
\hline & Df & res & $F$-value & $p$-value & res & $F$-value & $p$-value \\
\hline Extreme weather treatment & 1 & 15 & 1.603 & 0.225 & 13 & 7.852 & $0.015^{\star}$ \\
\hline Intraradical colonization per total root & Df & res & $F$-value & $p$-value & res & $F$-value & $p$-value \\
\hline Extreme weather treatment & 1 & 15 & 1.375 & 0.259 & 13 & 11.502 & $0.005^{\star}$ \\
\hline QD-apatite per total root & Df & res & $F$-value & $p$-value & res & $F$-value & $p$-value \\
\hline Extreme weather treatment & 1 & 39 & 0.923 & 0.343 & 29 & 9.880 & $0.004^{*}$ \\
\hline Mycorrhizal status & 1 & 39 & 0.169 & 0.684 & 29 & 1.704 & 0.202 \\
\hline Treatment $\times$ mycorrhizal status & 1 & 39 & 1.540 & 0.222 & 29 & 0.024 & 0.879 \\
\hline QD-apatite per total shoot & Df & res & $F$-value & $p$-value & res & $F$-value & $p$-value \\
\hline Extreme weather treatment & 1 & 39 & 0.056 & 0.814 & 29 & 2.046 & 0.163 \\
\hline Mycorrhizal status & 1 & 39 & 0.820 & 0.371 & 29 & 0.194 & 0.663 \\
\hline Treatment $\times$ mycorrhizal status & 1 & 39 & 0.954 & 0.335 & 29 & 0.559 & 0.461 \\
\hline
\end{tabular}

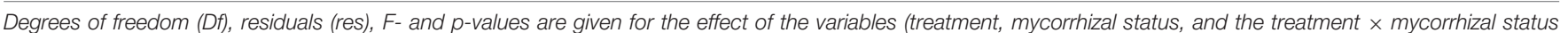
interaction). P-values in bold with an * have a significant effect of the variable ( $p$-value $<0.05)$.

We tested the effect of the heat treatment and mycorrhizal status on the nmol of QD-apatite per total root and total shoot by comparing the control plants to the heat-treated plants. We found that nmol of QD-apatite per total root was not significantly affected by treatment, mycorrhizal status or the treatment $\times$ mycorrhizal interaction (Table 2 and Figure 5A). Likewise, we found that nmol QDapatite per total of shoot was not significantly affected by treatment, mycorrhizal status or the interaction (Table 2 and Figure 5B).

We quantified the effect of the flooding treatment by comparing the flooded plants with the control plants. We found that the nmol QD-apatite per total root was significantly lower in the flooded treatment, compared to control plants, but was not significantly affected by the mycorrhizal status or the treatment $\times$ mycorrhizal interaction (Table 2 and Figure 5C). We found that nmol of QD-apatite per total shoot was not significantly affected by treatment, mycorrhizal status or the treatment $\times$ mycorrhizal status interaction (Table 2 and Figure 5D).

\section{DISCUSSION}

Our aim was to determine how extreme weather events, specifically soil heating and flooding, modified the $\mathrm{P}$ uptake of plants and plants colonized by arbuscular mycorrhizal fungi. We found a strong effect of the flooding treatment on plant survival, with over $60 \%$ of the plants dying when exposed to flooding. We found a less strong effect of the soil heating treatment, with $\sim 20 \%$ of the plants dying. We found no evidence that mycorrhizal colonization of $R$. irregularis had an effect on the survival rates of plants (Table 1), but this effect is known to be highly species specific (Camprubi et al., 2012).
It is well established that flooding drives a stress response in plants, including metabolic modifications, such as inhibition of mitochondrial respiration and photosynthesis, leading to dramatic decline in plant growth and development and concurrent dysfunctions (Parent et al., 2008). We found that flooding was linked to a decrease in plant biomass (Figures 2C,D), intraradical colonization (Figures 3C,D), and nutrient uptake (Figures 5C,D).

Heat is also known to disrupt many physiological and biophysical processes, including photosynthesis and chlorophyll synthesis (Zhu et al., 2017). However, we did not see strong treatment effects on plant performance under our soil heating regime (Figures 2A,B). The stronger effects of the flooding treatment in our study could potentially be linked to the biology of $M$. truncatula, a Mediterranean herb known to tolerate high temperatures, but to be very sensitive to flooding (Küster et al., 2006). Additionally, our heating regime was potentially less intense than expected in nature because we only increased the soil temperature, without decreasing the water availability. This has the potential to reduce the stress experienced by plants and fungi in the heating treatment.

\section{Mycorrhizal Fungi Affect Plant Biomass Allocation Under Extreme Weather Events}

We expected to find a positive effect of mycorrhizal colonization on plant biomass. While mycorrhizal status had no effect on total plant biomass, we found that mycorrhizal status influenced the biomass allocation to above and below ground plant parts. Mycorrhizal plants had a higher shoot biomass than nonmycorrhizal plants (Table $\mathbf{1}$ and Figure 2). This supports previous studies that have shown how arbuscular mycorrhizal fungi can modify biomass allocation of their host plants, 

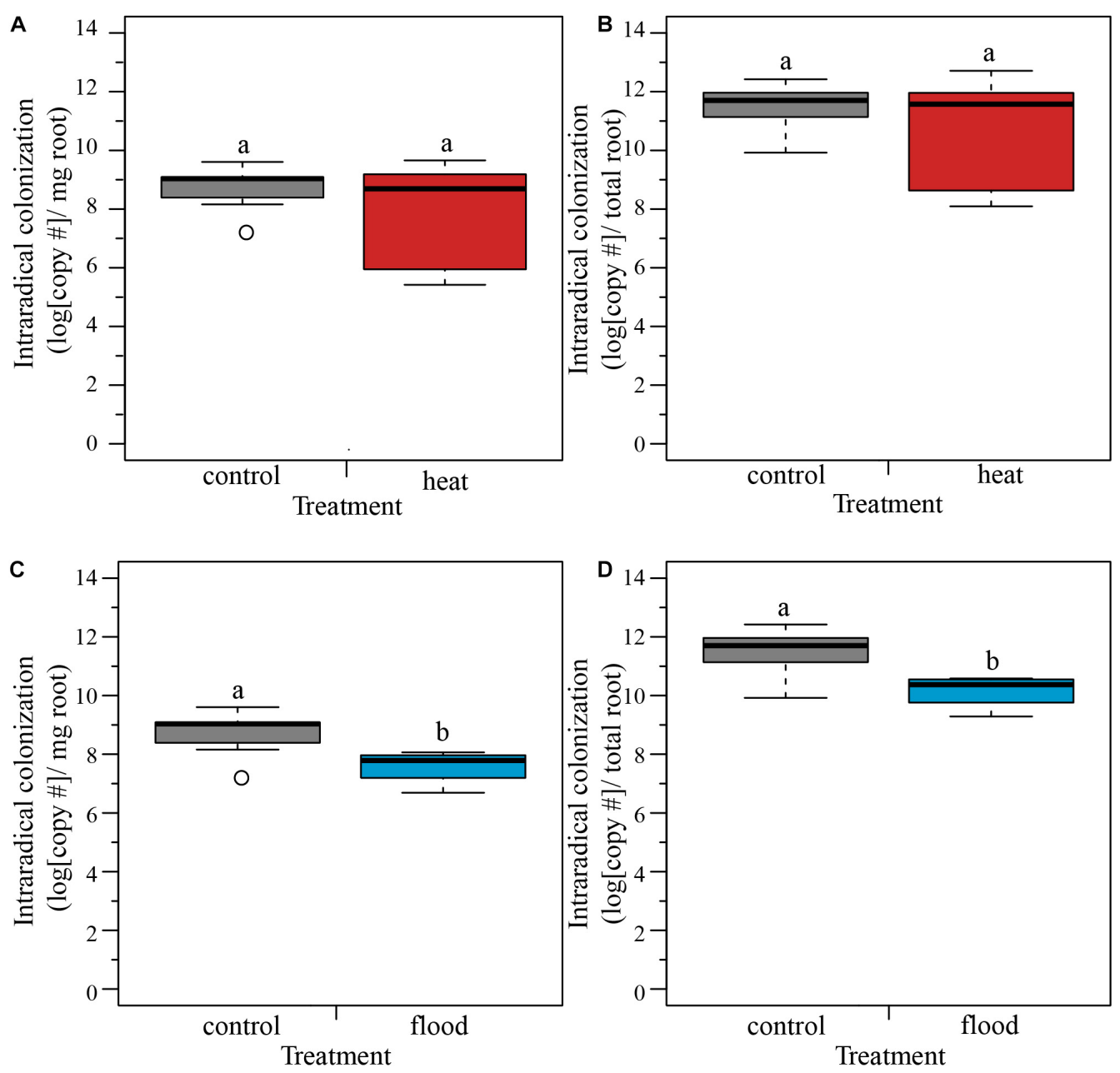

FIGURE 3 | Boxplots representing the intraradical colonization per mg and per total root. (A,B) The heat treatment did not significantly influence the fungal colonization of the host roots per mg or per total root. (C,D) The flooding treatment caused a significant lower intraradical colonization of the host roots, both per mg of root and per total root. $n_{\text {contol }}=12, n_{\text {heat }}=8, n_{\text {flood }}=4$. Top and bottom of the box indicate the first and third quartile, and the whiskers indicate the minimum and maximum values. Different letters indicate significant difference between the means ( $p$-value $<0.05)$.

with mycorrhizal plants having higher shoot mass than nonmycorrhizal plants (Johnson et al., 2008; Zaller et al., 2011; Zhang et al., 2011). Non-mycorrhizal plants, similar to plants under low water or low nutrient conditions, may allocate less biomass to the shoot and more the roots to increase the uptake of limiting resource (Zhang et al., 2011). Many studies have shown that plant stressors, such as water availability, temperature, and heavy metals can also influence the biomass allocation patterns because these stressors alter the carbon allocation of plants [reviewed in Andersen and Rygiewicz (1991)]. Likewise, we found the lowest shoot mass was found in non-mycorrhizal plants exposed to the flooded treatment (Table 1 and Figure 2).

\section{Flooding, but Not Heat, Decreases Mycorrhizal Colonization}

We then tested the effects of the extreme weather treatments on intraradical colonization rates as measured by qPCR. In flooded plants, we found that arbuscular mycorrhizal fungi showed a surprising resilience against the flooding treatment, still colonizing roots after a 7-day exposure to flooded conditions (Figures 3C,D). Previous research has demonstrated speciesspecific effects of colonization by arbuscular mycorrhizal fungi, with some plant-fungal combinations experiencing increased colonization associated with flooding, while others show a reduction, or no effect (Hartmond et al., 1987; Wu et al., 2013). There may also be an important time component: in rice, colonization of arbuscular mycorrhizal fungi gradually decreases over time during flooding condition due to changed root morphology (Vallino et al., 2014). Our study suggests that colonization is negatively affected by the flooding treatment, but did not lead to the total loss of mycorrhizal colonization.

In contrast to flooding, we found that the heat treatment did not influence the fungal colonization rates significantly (Figures 3A,B). One explanation is that our heat treatment was neither strong, nor long enough to trigger a negative effect on the fungal symbiont. When the soil temperature increases, the carbon 
exchange rate and the absorption of nutrients as $\mathrm{P}$ increases which could negate the negative effects of increased temperatures (Andersen and Rygiewicz, 1991). We aimed to induce only a heat stress, however the heat-treated plants might have experienced drought related effects as well. While the majority of work has found positive effects of AM fungi on drought tolerance (Bárzana et al., 2015; Quiroga et al., 2017; Li et al., 2019; Fracasso et al., 2020), a transcriptomic analysis in sorghum suggested that drought can negatively impact the functionality of the symbiosis (Varoquaux et al., 2019). Similar negative effects have been found in barley under higher AMF richness (Sendek et al., 2019). However, the vast majority of studies suggest that AMF can improve tolerance to temperature stress. AMF can enhance water and nutrient uptake, and induce plant production of ROS-scavenging anti-oxidant compounds, reduce oxidative stress, improve photosynthesis, and increase accumulation of osmolytes (Zhu et al., 2017). However, because these effects differ depending on host species, fungal species/fungal diversity, and soil type, there are many open questions as to how plantsoil biotic interactions will respond under climate change. New research has shown that even the presence versus absence of intrahyphal endobacteria in AM fungi such as Gigaspora margarita plays an important role in modulating stress (Chialva et al., 2020). More broadly, while it is known that plants can actively recruit microorganisms to buffer the environmental stress of drought (Naylor and Coleman-derr, 2018; Andreojimenez et al., 2019; Vigani et al., 2019; Veach et al., 2020), it is unknown how these microorganisms interact with the functionality of mycorrhizal roots.

\section{Mycorrhizal Status Did Not Increase Nutrient Transfer}

The use of QD-apatite to study $\mathrm{P}$ transfer from fungi to host plants is an emerging technique (Whiteside et al., 2019; van't Padje et al., 2020a,b), and many open questions remain. Using emission finger printing, we were able to quantify florescence in root and shoot tissue of QD-apatite injections of two different colors in whole plants, representing nutrient uptake from pre- and post-extreme weather treatments. Data on pretreatment uptake (i.e., red QDs, $\lambda=666 \mathrm{~nm}$ ) suggested that tagged apatite was taken up by plants, and then successfully transferred to growing leaves: shoots contained on average three times more QD-apatite than roots (Figure 4). This is important because it further validates our QD-apatite method (Whiteside et al., 2019), showing that tagged nutrients accumulated in the growing host shoots tissues as expected.

After the pre-treatment, we next quantified QD-apatite uptake post-extreme weather treatments. The most important result was that plants contained, on average, $80 \%$ less QD-apatite compared to QD-apatite from the pre-treatment injection, independent of treatment. This suggests that either the plants were saturated with $P$ from the first injection, or that not enough time had passed since the injection for the QD-apatite to be incorporated into host tissue (7 days). We found no significant effect of mycorrhizal status of the plants on QD uptake in the heat treatment (Table 2). This result is not surprising given that the heat treatment did not induce a change in plant biomass or mycorrhizal status. We did find that there was a significant effect of the flooding treatment on QD uptake in post-treatment QD injections: roots of flooded plants contained significantly less nmol QD-apatite than roots of control plants (Table 2 and Figure 5D). While research has shown that flooding can increase the solubility of $\mathrm{P}$ in soils by dissolution of $\mathrm{P}$ apatite (Chien, 1977), the lower root biomass and lower colonization of fungi in roots of flooded plants suggests that these host roots and fungal symbionts were stressed, and were not able to take up or transfer as much QD-apatite as control plants.

Our work provides further evidence that plants and arbuscular mycorrhizal fungi are able to take up QD-apatite, and incorporate
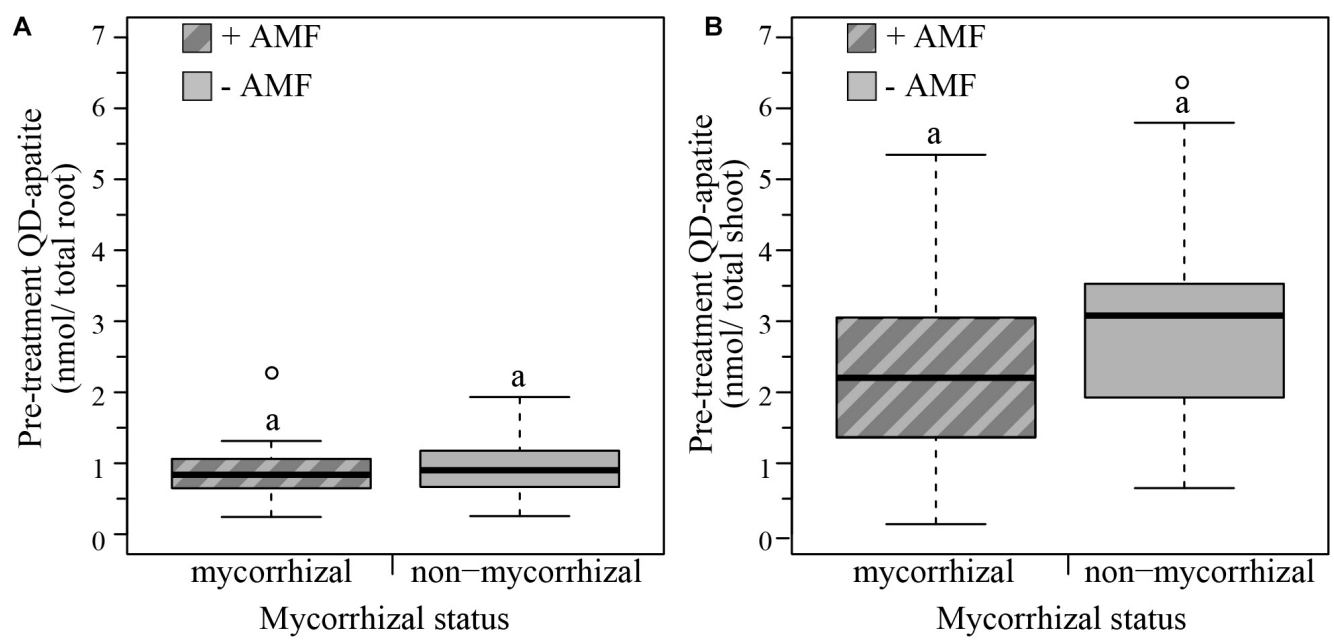

FIGURE 4 | Boxplots representing pre-treatment QD-apatite content per total root and total shoot for mycorrhizal (+AMF) and non-mycorrhizal plants (-AMF). (A) The amount QD-apatite in total roots was not significantly different between mycorrhizal and non-mycorrhizal plants. (B) The amount of QD-apatite in total shoots was also not significantly different between mycorrhizal and non-mycorrhizal plants. $n_{+A M F}=24, n_{-} A M F=28$. Top and bottom of the box indicate the first and third quartile, and the whiskers indicate the minimum and maximum values. Different letters indicate significant difference between the means $(p-v a l u e ~<0.05)$. 

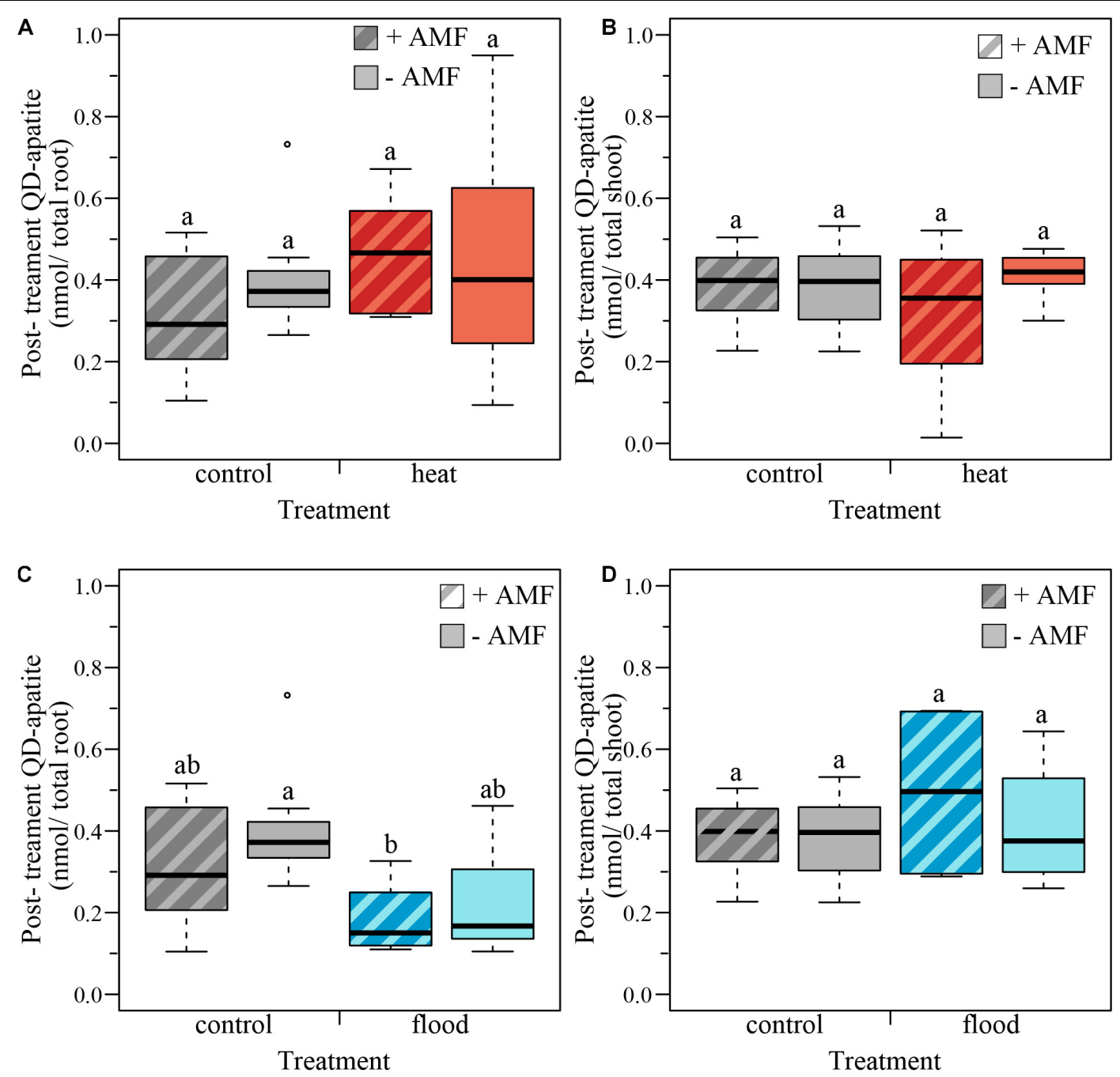

FIGURE 5 | Boxplots representing the post-treatment QD-apatite content per total root and total shoot for mycorrhizal (+AMF) and non-mycorrhizal plants (-AMF). (A) The amount QD-apatite in total root was not significantly affected by heat treatment, mycorrhizal status or the treatment $\times$ mycorrhizal status interaction. (B) The amount of QD-apatite was in total shoot was not significantly affected by the heat treatment, mycorrhizal status nor the treatment $\times$ mycorrhizal status interaction. (C) The amount of QD-apatite in total roots was significantly affected by the flooding treatment: flooded roots contained less QD-apatite. However, QD content was not significantly affected by mycorrhizal status or the treatment $\times$ mycorrhizal status interaction. (D) The amount of QD-apatite in shoots was not significantly affected by the flooded treatment, mycorrhizal status or the treatment $\times$ mycorrhizal status interaction. $n_{\text {Contol, }+ \text { AMF }}=12, n_{\text {Contol, }}-$ AMF $=12, n_{\text {heat },+A M F}=8, n_{\text {heat }}$, $-A M F=11, n_{\text {flood }}+A M F=4, n_{\text {flood }},-A M F=5$. Top and bottom of the box indicate the first and third quartile, and the whiskers indicate the minimum and maximum values. Different letters indicate significant difference between the means ( $p$-value $<0.05)$.

the fluorescing QD-apatite into their tissue (Figure 1; Whiteside et al., 2019; van't Padje et al., 2020a), as has been shown previously using QD-tagged amino acids (Whiteside et al., 2009, 2012a,b). However, a major limitation in our current approach is the inability to quantify the rate at which $\mathrm{P}$ is dissociated from the QD core across different biological tissue. Additionally, while the specific pathways of QD-apatite uptake in plants is still unknown, there has been work describing the mechanisms of nanoparticles by plants roots [extensively reviewed by Schwab et al. (2016)]. Uptake of larger QD particles is likely via endocytosis, i.e., invagination of the cell membrane. The most common endocytosis pathway in plant roots is clathrin dependent, enabling the uptake of particles of $\sim 70$ to $120 \mathrm{~nm}$ diameter (Šamaj, 2012), but nanoparticles can also be taken up via clathrin-independent endocytosis (Etxeberria et al., 2006). Once inside the plant root cell, the nanoparticles can cross the cells simplistically via cell wall pores. Previous studies have measured cell wall pores diameter, and found that the diameter varies between 5 and $20 \mathrm{~nm}$ (McCann et al., 1990). Transport of nanoparticles can also occur apoplastically and via the vascular system of the plants (reviewed in Schwab et al., 2016). Our data confirm past research in QDs showing that once inside the plant roots, the $\mathrm{QD}$ are transported to the shoots and eventually into the mesophyll cells and chloroplasts (Whiteside et al., 2009, 2019). 
Less is known about the fungal uptake of nutrients tagged with nanoparticles, especially in arbuscular mycorrhizal fungi. In yeast, QD tagged glutathione has been shown to be taken up using ADP1-encoded transporters (Gustafsson et al., 2015). However, for larger particles, such as apatite crystals used here, endocytosis is the most likely mechanism. This idea is supported by recent bright-field imaging videos of nutrient flows that showed large vacuoles inside hyphae when the fungus was given access to QD-tagged apatite. These large vacuoles were conspicuously absent in flows when the fungus has no access to QD-tagged apatite (van't Padje et al., 2020a). Endocytosis has been found to be important for particle uptake in filamentous fungal hyphae (Fischer-Parton et al., 2000; Read and Kalkman, 2003). Likewise, the budding yeasts Saccharomyces cerevisiae (Lu et al., 2016), and Candida albicans have been shown to use clathrin mediated endocytosis. In the case of C. albicans, endocytosis can result in invagination of vacuoles with diameters of $\sim 100 \mathrm{~nm}$ (Epp et al., 2013). Arbuscular mycorrhizal fungi likely rely on endocytosis for the uptake of QD-apatite crystals, which can be as large as $\sim 200 \mathrm{~nm}$ directly after chemical synthesis (Whiteside et al., 2019). However, as the fungi dissolute the apatite (Pel et al., 2018), the particle size will decrease prior to uptake $(\sim 8-20 \mathrm{~nm})$.

We did not find a significant effect of mycorrhizal status on the nmol of QD-apatite per total root or shoot. Past work has shown that can arbuscular mycorrhizal fungi facilitate the uptake of apatite in plants (Pel et al., 2018), likely through dissolution of the apatite into smaller crystals before uptake. Likewise, Whiteside et al., 2019 found that colonization by mycorrhizal fungi significantly increased QD-apatite in plant tissue after $\sim 7$ weeks. Given this past evidence, we had expected to see a positive effect of colonization on QD-apatite uptake for the host. However, given that we also did not see a positive effect of fungal colonization on total plant biomass, this is further evidence that not all plant-fungal combinations result in $\mathrm{P}$ benefits for host plants (Hoeksema et al., 2010) and that this is highly context dependent (Li et al., 2008; Chialva et al., 2020).

While some progress is being made in our ability to predict the effects of extreme weather events on single species, an open research question is how these events affect the interactions among species, and thus biodiversity more generally. Our work suggests that both plants and arbuscular mycorrhizal fungi were negatively affected by soil flooding, with plant survival, fungal

\section{REFERENCES}

Allen, M. R., Dube, O. P., Solecki, W., AragonÜDurand, F., Cramer, W., Humphreys, S., et al. (2018). "Framing and context," in Global warming of $1.5^{\circ} \mathrm{C}$. An IPCC Special Report on the Impacts of Global Warming of $1.5^{\circ} \mathrm{C}$ Above PreIndustrial Levels and Related Global Greenhouse Gas Emission Pathways, in the Context of Strengthening the Global Response to the Threat of Climate Change, Sustainable Development, and Efforts to Eradicate Poverty, eds V. MassonDelmotte, P. Zhai, H. O. Portner, D. Roberts, J. Skea, P. R. Shukla et al., 47-92.

Andersen, C. P., and Rygiewicz, P. T. (1991). Stress Interactions and mycorrhizal plant response: understanding carbon allocation priorities. Environ. Pollut. 73, 217-244. doi: 10.1016/0269-7491(91)90051-w

Andreo-jimenez, B., Vandenkoornhuyse, P., Van, A. L., Heutinck, A., Duhamel, M., Kadam, N., et al. (2019). Plant host and drought shape the root colonization and QD-apatite uptake decreasing under flooded conditions. These effects were less severe in the heat treatment. While we found no evidence that the plant-fungal combination tested affected $\mathrm{P}$ uptake by plants exposed to extreme weather events, future studies should develop a standardized protocol to test these and other weather-related stress effects, with the aim of developing databases on which predictive models can be constructed. As we test more species combinations to extreme weather, we can better understand how these events will shape biodiversity through symbiosis.

\section{DATA AVAILABILITY STATEMENT}

The datasets presented in this study can be found in online repositories. The names of the repository/repositories and accession number(s) can be found below: https://github.com/ anoukvantpadje/Extreme_weather.

\section{AUTHOR CONTRIBUTIONS}

AP and LC designed and performed the experiments. AP performed the statistical analysis and wrote the main text. PB was involved with revision of the main text. EK was involved in the experimental design and revision of the main text. All authors contributed to the article and approved the submitted version.

\section{FUNDING}

Research was supported by European Research Council ERC 335542, an Ammodo Foundation award, and an HFSP grant RGP0029 to EK.

\section{ACKNOWLEDGMENTS}

We thank the Department of Ecological Sciences for the facilities, Jurgen van Hal for maintaining the climate chambers, Matthew Whiteside for QD-development, and Malin Klein for technical support.

associated fungal microbiota in rice. PeerJ 7:e7463. doi: 10.7717/peerj. 7463

Barker, D. G., Pfaff, T., Moreau, D., Groves, E., Ruffel, S., Lepetit, M., et al. (2006). "Growing M. truncatula: choice of substrates and growth conditions," in Medicago Truncatula Handbook (Oklahoma: Samuel Roberts Noble Foundation).

Bárzana, G., Aroca, R., and Ruiz-Lozano, J. M. (2015). Localized and non-localized effects of arbuscular mycorrhizal symbiosis on accumulation of osmolytes and aquaporins and on antioxidant systems in maize plants subjected to total or partial root drying. Plant Cell Environ. 38, 1613-1627. doi: 10.1111/pce. 12507

Berruti, A., Lumini, E., Balestrini, R., and Bianciotto, V. (2016). Arbuscular mycorrhizal fungi as natural biofertilizers: let's benefit from past successes. Front. Microbiol. 6:1559.

Bronstein, J. L. (2015). Mutualism. Oxford: Oxford University Press. 
Brundrett, M. C., and Tedersoo, L. (2018). Evolutionary history of mycorrhizal symbioses and global host plant diversity. New Phytol. 220, 1108-1115. doi: 10.1111/nph.14976

Camprubi, A., Abril, M., Estaun, V., and Calvet, C. (2012). Contribution of arbuscular mycorrhizal symbiosis to the survival of psammophilic plants after sea water flooding. Plant Soil 351, 97-105. doi: 10.1007/s11104-011-0933-5

Chialva, M., Lanfranco, L., Guazzotti, G., Santoro, V., Novero, M., and Bonfante, P. (2020). Gigaspora margarita and its endobacterium modulate symbiotic marker genes in tomato roots under combined water and nutrient stress. Plants 9:886. doi: $10.3390 /$ plants 9070886

Chialva, M., Salvioli, di Fossalunga, A., Daghino, S., Ghignone, S., Bagnaresi, P., et al. (2018). Native soils with their microbiotas elicit a state of alert in tomato plants. New Phytol. 220, 1296-1308. doi: 10.1111/nph.15014

Chien, S. H. (1977). Dissolution of phosphate rocks in a flooded acid soil1. Soil Sci. Soc. Am. J. 41, 1106-1109. doi: 10.2136/sssaj1977.03615995004100060018x

Chomicki, G., and Renner, S. S. (2017). Partner abundance controls mutualism stability and the pace of morphological change over geologic time. Proc. Natl. Acad. Sci. U. S. A. 114, 3951-3956. doi: 10.1073/pnas.1616837114

Chomicki, G., Weber, M., Antonelli, A., Bascompte, J., and Kiers, E. T. (2019). The impact of mutualisms on species richness. Trends Ecol. Evol. 34, 698-711. doi: 10.1016/j.tree.2019.03.003

Dakos, V., and Bascompte, J. (2014). Critical slowing down as early warning for the onset of collapse in mutualistic communities. Proc. Natl. Acad. Sci. 111, 17546-17551. doi: 10.1073/pnas.1406326111

Declerck, S., Fortin, J. A., and Strullu, D. G. (2005). In Vitro Culture of Mycorrhizas. Berlin: Springer.

Edwards, M., and Richardson, A. J. (2004). Impact of climate change on marine pelagic phenology and trophic mismatch. Nature 430, 881-884. doi: 10.1038/ nature 02808

Engelmoer, D. J. P., Behm, J. E., and Kiers, E. T. (2014). Intense competition between arbuscular mycorrhizal mutualists in an in vitro root microbiome negatively affects total fungal abundance. Mol. Ecol. 23, 1584-1593. doi: 10. $1111 /$ mec. 12451

Epp, E., Nazarova, E., Regan, H., Douglas, L. M., Konopka, J. B., Vogel, J., et al. (2013). Clathrin- and arp2/3-independent endocytosis in the fungal pathogen Candida albicans. MBio 4, e476-e413.

Etxeberria, E., Gonzalez, P., Baroja-Fernández, E., and Romero, J. P. (2006). Fluid phase endocytic uptake of artificial nano-spheres and fluorescent quantum dots by sycamore cultured cells. Plant Signal. Behav. 1, 196-200. doi: 10.4161/psb.1. 4.3142

Fischer-Parton, S., Parton, R. M., Hickey, P. C., Dijksterhuis, J., Atkinson, H. A., and Read, N. D. (2000). Confocal microscopy of FM4-64 as a tool for analysing endocytosis and vesicle trafficking in living fungal hyphae. J. Microsc. 198, 246-259. doi: 10.1046/j.1365-2818.2000.00708.x

Fracasso, A., Telò, L., Lanfranco, L., Bonfante, P., and Amaducci, S. (2020). Physiological beneficial effect of rhizophagus intraradices inoculation on tomato plant yield under water deficit conditions. Agronomy 10:71. doi: 10 . 3390/agronomy10010071

Garcia, J., Barker, D. G., and Journet, E.-P. (2006). "Seed storage and germination,” in Medicago Truncatula Handbook (Oklahoma: The Samuel Roberts Noble Foundation).

Gardner, J. L., Rowley, E., De Rebeira, P., De Rebeira, A., and Brouwer, L. (2017). Effects of extreme weather on two sympatric australian passerine bird species. Philos. Trans. R. Soc. B Biol. Sci. 372:20160148. doi: 10.1098/rstb.2016.0148

Gustafsson, F. S., Whiteside, M. D., Jiranek, V., and Durall, D. M. (2015). Development and use of a quantum dot probe to track multiple yeast strains in mixed culture. Sci. Rep. 4:6971.

Harrison, R. D. (2000). Repercussions of El Niño: drought causes extinction and the breakdown of mutualism in Borneo. Proc. R. Soc. London. Ser. B Biol. Sci. 267, 911-915.

Hartmond, U., Schaesberg, N. V., Graham, J. H., and Syvertsen, J. P. (1987). Salinity and flooding stress effects on mycorrhizal and non-mycorrhizal citrus rootstock seedlings. Plant Soil 104, 37-43. doi: 10.1007/bf02370622

Hoagland, R., and Arnon, I. (1950). The Water-Culture Method for Growing Plants Without Soil. Berkeley, CA: The College of Agriculture.

Hoeksema, J. D., Chaudhary, V. B., Gehring, C. A., Johnson, N. C., Karst, J., Koide, R. T., et al. (2010). A meta-analysis of context-dependency in plant response to inoculation with mycorrhizal fungi. Ecol. Lett. 13, 394-407. doi: 10.1111/j.1461-0248.2009.01430.x

Husna, R., Mansur, I., and Kusmana, C. (2016). Growth and nutrient status of kayu kuku [pericopsis mooniana (Thw.) Thw] with mycorrhiza in soil media of nickel post mining site. Pakistan J. Biol. Sci. 19, 158-170. doi: 10.3923/pjbs. 2016.158.170

IPCC (2014). "Climate change 2014: impacts, adaptation, and vulnerability," in Part A: Global and Sectoral Aspects. Contribution of Working Group II to the Fifth Assessment Report of the Intergovernmental Panel on Climate Change, eds C. B. Field, V. R. Barros, D. J. Dokken, K. J. Mach, M. D. Mastrandrea, T. E. Bilir et al. (Cambridge: Cambridge University Press), 1132.

Jiang, Y., Wang, W., Xie, Q., Liu, N., Liu, L., Wang, D., et al. (2017). Plants transfer lipids to sustain colonization by mutualistic mycorrhizal and parasitic fungi. Science 356, 1172-1173. doi: 10.1126/science.aam9970

Johnson, N. C., Rowland, D. L., Corkidi, L., and Allen, E. B. (2008). Plant winners and losers during grassland N-Eutrophication differ in biomass allocation and mycorrhizas. Ecology 89, 2868-2878. doi: 10.1890/07-1394.1

Jordano, P. (2016). Chasing ecological interactions. PLoS Biol. 14:e1002559. doi: 10.1371/journal.pbio.1002559

Kawashita, M., Taninai, K., Li, Z., Ishikawa, K., and Yoshida, Y. (2012). Preparation of low-crystalline apatite nanoparticles and their coating onto quartz substrates. J. Mater. Sci. Mater. Med. 23, 1355-1362. doi: 10.1007/s10856-012-4614-6

Keymer, A., Pimprikar, P., Wewer, V., Huber, C., Brands, M., Bucerius, S. L., et al. (2017). Lipid transfer from plants to arbuscular mycorrhiza fungi. Elife 6:e29107.

Kiers, E. T., Duhamel, M., Beesetty, Y., Mensah, J. A., Franken, O., Verbruggen, E., et al. (2011). Reciprocal rewards stabilize cooperation in the mycorrhizal symbiosis. Science 333, 880-882. doi: 10.1126/science.1208473

Küster, H., Becker, A., Samac, D., and Tesfaye, M. (2006). The Medicago Truncatula Handbook. Oklahoma: Samuel Roberts Noble Foundation.

Li, H., Smith, F. A., Dickson, S., Holloway, R. E., and Smith, S. E. (2008). Plant growth depressions in arbuscular mycorrhizal symbioses: not just caused by carbon drain? New Phytol. 178, 852-862. doi: 10.1111/j.1469-8137.2008.02410. $\mathrm{x}$

Li, J., Meng, B., Chai, H., Yang, X., Song, W., Li, S., et al. (2019). Arbuscular mycorrhizal fungi alleviate drought stress in C3 (Leymus chinensis) and C4 (Hemarthria altissima) grasses via altering antioxidant enzyme activities and photosynthesis. Front. Plant Sci. 10:499.

Lu, R., Drubin, D. G., and Sun, Y. (2016). Clathrin-mediated endocytosis in budding yeast at a glance. J. Cell Sci. 129, 1531-1536. doi: 10.1242/jcs.182303

Luginbuehl, L. H., Menard, G. N., Kurup, S., Van Erp, H., Radhakrishnan, G. V., Breakspear, A., et al. (2017). Fatty acids in arbuscular mycorrhizal fungi are synthesized by the host plant. Science 356, 1175-1178. doi: 10.1126/science. aan0081

Martinez-Medina, A., Flors, V., Heil, M., Mauch-Mani, B., Pieterse, C. M. J., Pozo, M. J., et al. (2016). Recognizing plant defense priming. Trends Plant Sci. 21, 818-822. doi: 10.1016/j.tplants.2016.07.009

McCann, M. C., Wells, B., and Roberts, K. (1990). Direct visualization of cross-links in the primary plant cell wall. J. Cell Sci. 96, 323-334.

Meier, S., Cornejo, P., Cartes, P., Borie, F., Medina, J., and Azcón, R. (2015). Interactive effect between $\mathrm{Cu}$-adapted arbuscular mycorrhizal fungi and biotreated agrowaste residue to improve the nutritional status of Oenothera picensis growing in Cu-polluted soils. J. Plant Nutr. Soil Sci. 178, 126-135. doi: 10.1002/jpln.201400092

Millar, N. S., and Bennett, A. E. (2016). Stressed out symbiotes: hypotheses for the influence of abiotic stress on arbuscular mycorrhizal fungi. Oecologia 182, 625-641. doi: 10.1007/s00442-016-3673-7

Mohan, J. E., Cowden, C. C., Baas, P., Dawadi, A., Frankson, P. T., Helmick, K., et al. (2014). Mycorrhizal fungi mediation of terrestrial ecosystem responses to global change: mini-review. Fungal Ecol. 10, 3-19. doi: 10.1016/j.funeco.2014. 01.005

Naylor, D., and Coleman-derr, D. (2018). Drought stress and root-associated bacterial communities. Front. Plant Sci. 8:2223.

Parent, C., Capelli, N., Berger, A., Crèvecoeur, M., James, D., and Dat, F. (2008). An overview of plant responses to soil waterlogging. Plant Stress 2, 20-21.

Pel, R., Dupin, S., Schat, H., Ellers, J., Kiers, E. T., and van Straalen, N. M. (2018). Growth benefits provided by different arbuscular mycorrhizal fungi to Plantago 
lanceolata depend on the form of available phosphorus. Eur. J. Soil Biol. 88, 89-96. doi: 10.1016/j.ejsobi.2018.07.004

Quiroga, G., Erice, G., Aroca, R., Chaumont, F., and Ruiz-Lozano, J. M. (2017). Enhanced drought stress tolerance by the arbuscular mycorrhizal symbiosis in a drought-sensitive maize cultivar is related to a broader and differential regulation of host plant aquaporins than in a drought-tolerant cultivar. Front. Plant Sci. 8:1056.

Ray, A. M., Gould, W. R., Hossack, B. R., Sepulveda, A. J., Thoma, D. P., Patla, D. A., et al. (2016). Influence of climate drivers on colonization and extinction dynamics of wetland-dependent species. Ecosphere 7:e01409.

Read, N. D., and Kalkman, E. R. (2003). Does endocytosis occur in fungal hyphae? Fungal Genet. Biol. 39, 199-203. doi: 10.1016/s1087-1845(03)00045-8

Rosenzweig, C., Iglesias, A., Yang, X. B., Epstein, P. R., and Chivian, E. (2015). Climate change and extreme weather events: free papers. Int. J. Epidemiol. 44, 90-91.

Šamaj, J. (2012). Endocytosis in Plants. Berlin: Springer.

Schwab, F., Zhai, G., Kern, M., Turner, A., Schnoor, J. L., and Wiesner, M. R. (2016). Barriers, pathways and processes for uptake, translocation and accumulation of nanomaterials in plants - critical review. Nanotoxicology 10, 257-278. doi: 10.3109/17435390.2015.1048326

Sendek, A., Karakoç, C., Wagg, C., Domínguez-Begines, J., do Couto, G. M., van der Heijden, M. G. A., et al. (2019). Drought modulates interactions between arbuscular mycorrhizal fungal diversity and barley genotype diversity. Sci. Rep. 9:9650.

Smith, S. E., Jakobsen, I., Gronlund, M., and Smith, F. A. (2011). Roles of arbuscular mycorrhizas in plant phosphorus nutrition: interactions between pathways of phosphorus uptake in arbuscular mycorrhizal roots have important implications for understanding and manipulating plant phosphorus acquisition. Plant Physiol. 156, 1050-1057. doi: 10.1104/pp.111.174581

Spatafora, J. W., Chang, Y., Benny, G. L., Lazarus, K., Smith, M. E., Berbee, M. L., et al. (2016). A phylum-level phylogenetic classification of zygomycete fungi based on genome-scale data. Mycologia 108, 1028-1046. doi: 10.3852/16-042

Sun, S., Chan, L. S., and Li, Y.-L. (2014). Flower-like apatite recording microbial processes through deep geological time and its implication to the search for mineral records of life on Mars. Am. Mineral. 99, 2116-2125. doi: 10.2138/am2014-4794

Tang, I.-M., Krishnamra, N., Charoenphandhu, N., Hoonsawat, R., and PonOn, W. (2010). Biomagnetic of apatite-coated cobalt ferrite: a core-shell particle for protein adsorption and ph-controlled release. Nanoscale Res. Lett. 6:19.

Tedersoo, L., Bahram, M., and Zobel, M. (2020). How mycorrhizal associations drive plant population and community biology. Science 367: eaba1223. doi: 10.1126/science.aba1223

Thonar, C., Erb, A., and Jansa, J. (2012). Real-time PCR to quantify composition of arbuscular mycorrhizal fungal communities-marker design, verification, calibration and field validation. Mol. Ecol. Resour. 12, 219-232. doi: 10.1111/ j.1755-0998.2011.03086.x

Tinsley, R. C., Stott, L. C., Viney, M. E., Mable, B. K., and Tinsley, M. C. (2015). Extinction of an introduced warm-climate alien species, Xenopus laevis, by extreme weather events. Biol. Invasions 17, 3183-3195. doi: 10.1007/s10530015-0944-x

Vallino, M., Fiorilli, V., and Bonfante, P. (2014). Rice flooding negatively impacts root branching and arbuscular mycorrhizal colonization, but not fungal viability. Plant Cell Environ. 37, 557-572. doi: 10.1111/pce.12177

van't Padje, A., Oyarte Galvez, L., Klein, M., Hink, M. A., Postma, M., Shimizu, T., et al. (2020a). Temporal tracking of quantum-dot apatite across in vitro mycorrhizal networks shows how host demand can influence fungal nutrient transfer strategies. ISME J. 15, 435-449. doi: 10.1038/s41396-020-00786-w

van't Padje, A., Werner, G. D. A., and Kiers, E. T. (2020b). Mycorrhizal fungi control value of phosphorus in trade symbiosis with host roots when exposed to abrupt 'crashes' and 'booms' of resource availability. New Phytol. 229, 29332944. doi: 10.1111/nph.17055

Varoquaux, N., Cole, B., Gao, C., Pierroz, G., Baker, C. R., Patel, D., et al. (2019). Transcriptomic analysis of field-droughted sorghum from seedling to maturity reveals biotic and metabolic responses. Proc. Natl. Acad. Sci. 116, 27124-27132. doi: 10.1073/pnas.1907500116
Veach, A. M., Chen, H., Yang, Z. K., Labbe, A. D., Engle, N. L., Tschaplinski, T. J., et al. (2020). Plant hosts modify belowground microbial community response to extreme drought. Am. Soc. Microbiol. 5, e92-e20.

Vigani, G., Rolli, E., Marasco, R., Orto, M. D., Michoud, G., Soussi, A., et al. (2019). Root bacterial endophytes confer drought resistance and enhance expression and activity of a vacuolar $\mathrm{H}+$-pumping pyrophosphatase in pepper plants. Environ. Microbiol. 21, 3212-3228. doi: 10.1111/1462-2920.14272

Werner, G. D. A., Cornelissen, J. H. C., Cornwell, W. K., Soudzilovskaia, N. A., Kattge, J., West, S. A., et al. (2018). Symbiont switching and alternative resource acquisition strategies drive mutualism breakdown. Proc. Natl. Acad. Sci. 115, 5229-5234. doi: 10.1073/pnas.1721629115

Whiteside, M. D., Digman, M. A., Gratton, E., and Treseder, K. K. (2012a). Organic nitrogen uptake by arbuscular mycorrhizal fungi in a boreal forest. Soil Biol. Biochem. 55, 7-13. doi: 10.1016/j.soilbio.2012.06.001

Whiteside, M. D., Garcia, M. O., and Treseder, K. K. (2012b). Amino acid uptake in arbuscular mycorrhizal plants. PLoS One 7:e47643. doi: 10.1371/journal.pone. 0047643

Whiteside, M. D., Treseder, K. K., and Atsatt, P. R. (2009). The brighter side of soils: quantum dots track organic nitrogen through fungi and plants. Ecology 90, 100-108. doi: 10.1890/07-2115.1

Whiteside, M. D., Werner, G. D. A., Caldas, V. E. A., van 't Padje, A., Dupin, S. E., and Elbers, B. (2019). Mycorrhizal fungi respond to resource inequality by moving phosphorus from rich to poor patches across networks. Curr. Biol. 29, 2043-2050.e8

Wu, Q. S. (2017). Arbuscular Mycorrhizas and Stress Tolerance of Plants. Singapore: Springer.

Wu, Q. S., Zou, Y. N., and He, X. H. (2010). Contributions of arbuscular mycorrhizal fungi to growth, photosynthesis, root morphology and ionic balance of citrus seedlings under salt stress. Acta Physiol. Plant. 32, 297-304. doi: 10.1007/s11738-009-0407-z

Wu, Q. S., Zou, Y. N., and Huang, Y. M. (2013). The arbuscular mycorrhizal fungus Diversispora spurca ameliorates effects of waterlogging on growth, root system architecture and antioxidant enzyme activities of citrus seedlings. Fungal Ecol. 6, 37-43. doi: 10.1016/j.funeco.2012.09.002

Zaller, J. G., Frank, T., and Drapela, T. (2011). Soil sand content can alter effects of different taxa of mycorrhizal fungi on plant biomass production of grassland species. Eur. J. Soil Biol. 47, 175-181. doi: 10.1016/j.ejsobi.2011.03.001

Zhang, Q., Zhang, L., Weiner, J., Tang, J., and Chen, X. (2011). Arbuscular mycorrhizal fungi alter plant allometry and biomassdensity relationships. Ann. Bot. 107, 407-413. doi: 10.1093/aob/mcq249

Zhou, Y., Newman, C., Chen, J., Xie, Z., and Macdonald, D. W. (2013). Anomalous, extreme weather disrupts obligate seed dispersal mutualism: snow in a subtropical forest ecosystem. Glob. Chang. Biol. 19, 2867-2877. doi: 10. $1111 /$ gcb. 12245

Zhu, X., Song, F., and Liu, F. (2017). “Arbuscular mycorrhizal fungi and tolerance of temperature stress in plants," in Arbuscular Mycorrhizas and Stress Tolerance of Plants, ed. Q. S. Wu (Singapore: Springer).

Zimmermann, T., Rietdorf, J., and Pepperkok, R. (2003). Spectral imaging and its applications in live cell microscopy. FEBS Lett. 546, 87-92. doi: 10.1016/s00145793(03)00521-0

Zylstra, E. R., Swann, D. E., Hossack, B. R., Muths, E., and Steidl, R. J. (2019). Drought-mediated extinction of an arid-land amphibian: insights from a spatially explicit dynamic occupancy model. Ecol. Appl. 29: e01859.

Conflict of Interest: The authors declare that the research was conducted in the absence of any commercial or financial relationships that could be construed as a potential conflict of interest.

Copyright (๑) 2021 van 't Padje, Bonfante, Ciampi and Kiers. This is an open-access article distributed under the terms of the Creative Commons Attribution License (CC BY). The use, distribution or reproduction in other forums is permitted, provided the original author(s) and the copyright owner(s) are credited and that the original publication in this journal is cited, in accordance with accepted academic practice. No use, distribution or reproduction is permitted which does not comply with these terms. 